\title{
On Image Narration Features and Artistry of Wordless Picture Books-A Case Study of Arrival Shanshan Chen
}

\author{
Quanzhou Preschool Education College, Quanzhou , 362000, China
}

Keywords: wordless picture books, image narration, Arrival

\begin{abstract}
Wordless picture book is a literary genre which narrates and expresses ideas of stories by completely relying on visual images, and thus plays an important role in children's education at primary stage. With an important time-based feature, image narration of wordless picture books applies montage technique, opens a space in time, connects a large amount of frozen single picture fragments into a continuous narration integrity, promotes the process of narration through corresponding plot design and displacement of time and space, and delays readers' reading time with picture and detail skills, so that wordless picture books have stories full of tension and unique artistic charm. This paper discusses about image narration features and artistry of wordless picture books with the example of Arrival.

From the perspective of preschool education, image narrative language of wordless picture books can help children improve their aesthetics, language skills, thinking ability and comprehensive ability etc substantially, and good wordless picture books can play an important supporting role in children's growth in terms of ideology and culture and lay a solid foundation for their future development. From the perspective of art, compared with other children's literature forms, wordless picture books have huge advantages in terms of children's education, and have unique literary value and artistic connotation by integrating knowledge and stories perfectly with painting art in image narration. This paper analyzes the classic wordless picture book Arrival, and elaborates image narration features and artistry of wordless picture books in detail, with the hope of promoting the popularization progress of wordless picture books in Chinese children's education circle and facilitating better development of children's education.
\end{abstract}

\section{Wordless picture books and Arrival}

(I) Concept of wordless picture book

Wordless picture book specifically refers to a children's literary genre of picture book which conveys thoughts, presents plots and extends stories by connecting images systematically according to relations among images with visual images as the carrier. In traditional definition, wordless picture books contain no words and express stories by relying completely on visual images. In fact, however, wordless picture book is not really wordless, as text is needed in book cover, flyleaf and book title etc in order to express main ideas of works; onomatopoeia and mimetic words etc occur occasionally in formal documents to make visual images more profound through simple acoustic information; landmarks of scenes or environment would also display relevant text message, such as advertising boards in stores and notes of main characters etc; besides, authors would also use simple words and phrases at the beginning and in the end of each article to ensure integrity. Such texts in image narration of wordless picture books add relatively real scenes to narration and help readers understand creation intentions of authors while reading. So, wordless picture books are not picture books which haven't texts in the simple sense, but weaken the sense of presence of texts by image narration, minimize the amount of text information, and basically realize expression of story plots in image narration, so that readers feel more acceptable about stories. Wordless picture books apply to children's education and can truly promote rapid development of children's literary education.

(II) Brief introduction to Arrival

Arrival mainly tells about the story of an immigrant. In this story, the hero leaves his hometown resolutely with great expectations of all family members out of yearning for good life and pursuit of dream, and comes to a completely strange country across the sea. However, the journey of pursuing 
dream is doomed to be bumpy. After arriving in this unfamiliar country, he feels pressure and challenges from all aspects-huge differences in customs, languages and values, loneliness and homesickness etc. But fortunately, the country that he chooses has simple and honest people. With friendly help of local people, he gradually survives on this foreign land, finds touching stories of many immigrants like him, and finally reunites with family members through unremitting efforts and makes his family live a happy life.

\section{Image narration features and artistry of wordless picture books with the example of Arrival}

(I) Overview of image narration features and artistry of wordless picture books

With creation carrier of visual images, wordless picture books have generally narration features and artistry including realism, abstraction, exaggeration, decoration and time basis. The so-called realism refers that authors describe accurately the modeling, thinking, feelings and behaviors etc of characters in creation according to external contours of characters and things in order to make picture books have a realistic style, so that children readers could have story reappear practically in brain according to images while reading and thus such picture books are more educational for children; abstraction refers that authors haven't complex description of pictures and do not show common and relatively familiar characters or things on pictures while creating picture books, but merely complete texture of pictures by simply using colors, symbols, points, lines and planes etc and convey their emotions through features of such colors or shapes; exaggeration is easier to understand and more popular among children compared with abstraction, and authors of such picture books often use exaggerated images to attract readers and apply simple colors and lines to constitute changing forms, actions and expressions, and although the original images of things are exaggerated, the exaggerated pictures are more lovely and naïve that meet psychological needs of children readers, attract readers' attention to stories and thus play an educational role; decoration has also its unique charm as the most common picture narration feature. Construction of plane visual images by combining organically points, lines and planes or introducing other elements is quite common in picture books. Decoration feature of image narration can be reflected by inserting these images into pictures with specific plots, so as to enhance the ornamental value of pictures and give people gorgeous and varied visual effects. Although the above mentioned features of image narration play an important role in style expression of wordless picture books, the most important feature is time basis. In narration of wordless picture books by an image language, time running of story plots is often driven by setting specific contact information of relevant plots and using spatial displacement etc, and readers' reading time of wordless picture books is delayed by using effects of details, implications and unique pictures to influence readers' thinking, so that image narration of picture books has an obvious time-based feature, which is analogous to "montage" technique in film processing. This paper analyzes time-based narration feature and artistry of Arrival by montage technique in subsequent discussion.

(II) Time-based image narration feature and artistry of wordless picture books

Wordless picture books have a great attraction to children mainly because of time-based narration feature. In creation of most of picture books, authors have unconscious concern and expression of the time-based feature, strengthen picture attractiveness by dealing with details and implications, and show a modern literary concept of combining pictures with texts, and their mastery of time-based feature is of important influence on the structural force of works. From the perspective of creation practice of practical wordless picture books, classic ones have an obvious time-based feature. However, according to current researches of scholars from all countries on the time-based image narration feature of wordless picture books, such feature can't be elaborated clearly. Since ancient times, a large number of scholars and ideologists have studied on concepts of time and space, and finally think that time can only be felt from movement and changes of things for common people, while life-oriented classic view of time and space is time-based feature of wordless picture book art.

Generally, like other traditional literary forms, wordless picture book has a universal feature of 
linear development and ensures continuity of stories by connecting every single word or phrase. Although not all stories have a strong continuity, the beginning and ending of stories are of certain necessary connection as stories are created around a subject, and thus wordless picture books meet relevant linear law of traditional narrative art. By viewing wordless picture book as a literary individual, it can be found that linear story lines of picture books are essentially controlled by picture time although representing a spatial feature superficially, and such regulation and control are unified with narration of story development. In specific creation of wordless picture books, authors separate story fragments from normal time to form completely independent "individual" time periods and thus constitute pictures. Here, authors shall make normal time spatial during separation out of picture freezing, show merely scene of a moment, and then meet the normal attribute of flying time through connection with pictures on the next page, and thus complete the mission of creating reading value for readers. Such "individual” time periods combining superficial image narration with inner literal narration are exactly originated from time-based feature of narrative art, and are the fundamental support of composition of wordless picture books.

(III) Application of "montage" technique in image narration of Arrival

Montage technique, which is actually a quite specific narrative art structure, firstly constitutes single lenses, and then forms complete narration by connecting single lenses selectively, and creates appropriate space in time constitution. Time-based feature of image narration in Arrival is almost the same with expression technique of montage, or montage technique is applied in image narration of Arrival. Arrival contains a large amount of frozen and relatively independent static pictures that can be connected, and some of these pictures simply record continuous movement, while some contain interlaced contexts before and after paragraphs. By connecting single pictures via montage technique, Arrival breaks restraints of time and space of traditional picture books in terms of narrative art and changes the original narrative rhythm. The author adjusts appropriately the time of narration pictures in the same part to be longer or shorter in creation, coordinates and organizes movement of characters, to make the story have a stronger rhythm. For instance, at the beginning of story, the author draws nine completely different ornaments in the picture, and these nine ornaments are all described in subsequent indoor panoramic views along with story progress. Again, in a picture which describes the hero packing, the author shows fully hand movement of the hero by close-up and expresses movement rhythm. In over one hundred pages of image narration in Arrival, sub-lens narration accounts for more than half, one page is divided into 12 small units at most, there are 9 panoramic views organized in complete accordance with time and place etc of the story, and the narration has strong logic effects.

Montage technique has generally two basic functions, namely expression of narration and transcendence of narration. Montage narration mainly decomposes relevant movement simply, while transcendence of narration focuses more on expression in thinking consciousness. The author applies a lot of metaphor and symbolic element image symbols to reflect the most realistic world in the form of wordless picture book.

In terms of "monster" image in Arrival, monster is a common decorative symbol in pictures of Arrival and has symbolic significance. For monster image in Arrival, monsters in two different cities have distinctive differences. In the foreign country, monsters are relatively obedient even with quite peculiar shapes. For example, the monster holding a big egg with huge wings and standing tall and upright in the city center and the monster adopted by the hero as a pet etc are common in human life and live with human beings harmoniously. However, it is significantly different in the hero's hometown, where monsters are not completely described by the author. But a mysterious atmosphere can be seen from a part of this. In the first chapter of this picture book, the author describes monsters by using metaphor technique: shows the gloomy and mysterious city with a large panoramic view, and describes the huge tail of monster on a blue-white wall, making the hero's house in the lower left corner of picture humble and tiny in contrast. By comparing two kinds of monsters, the author implies differences in living environment, and on the one hand satirizes and criticizes the dark world, and on the other hand expresses yearning and praise for a good life, which not only enhances the attractiveness of the picture book but also deepens theme and thoughts of the 
story.

\section{Conclusions}

Like other literary arts, wordless picture book learns gradually from advantages of various arts appropriately during its specific development, and has formed a set of unique image narration art creation standards. Arrival, as a representative work of wordless picture book art towards maturity, has more complex narration techniques than other picture books, has creative ideas no longer restricted in enlightenment of children, but expounds serious issues such as wars, death and racial prejudice etc, shows the glory of human nature, and sublimates ideological connotation of the work to a philosophical level.

\section{References}

[1] Huang Dan. Analysis of Narrative Elements of Picture Books and Study on the Image-text Relation [D]. Nanchang University, 2010.

[2] Qi Tongwei. Repair of Memory: Organization and Explanation of Contemporary Chinese History of Original Picture Books [D]. Zhejiang Normal University, 2010.

[3] Zhao Qiong. Study on Narrative Space of Picture Books [D]. Shanghai Normal University, 2011. 